\title{
A Potential Crack in our Experience with Bisphosphonate Therapy
}

\author{
Charles N. Cornell, MD
}

Received: 20 November 2015/Accepted: 1 December 2015/Published online: 6 January 2016

(C) Hospital for Special Surgery 2016

With the coming of this New Year, we proudly present the 12th volume of the HSS Journal. The readership of the Journal continues to expand, and interest in its content is growing around the world. The entire editorial board wishes our readership success in 2016, and we will welcome your participation and your contributions to the Journal in the coming year.

I wish to draw your attention to the article submitted by Jordan Villa, MD, Arianna Gianakos, BS and Joseph M. Lane, MD entitled Bisphosphonate Treatment in Osteoporosis: Optimal Duration of Therapy and the Incorporation of a Drug Holiday. In this paper, the authors provide a thorough review of the importance of bisphosphonates in the treatment of osteoporosis, the risk of complications associated with bisphosphonate treatment, and a well-conceived argument for the incorporation of a drug holiday in treatment regimens using these agents. In my opinion, this is a must-read article for any involved in caring for patients in the musculoskeletal disciplines.

In the fall of 1986, I was privileged to serve as the Metabolic Bone Disease Fellow at HSS. Under Joe Lane's leadership, we struggled to manage patients with osteoporosis, a crippling disease, for which there was no effective treatment. Estrogen replacement therapy and drugs like sodium fluoride or first generation bisphosphonates were not effective and carried unacceptable risks and side effects. The appearance of the amino bisphosphonates was practically a miracle and for the first time provided medications that reduced the risk of both hip and vertebral fracture in patients with documented osteoporosis.
Unfortunately, the potential negative consequence of over treatment with these drugs was overlooked in the zeal of their application and rare but severe complications of overuse appeared.

Villa and her coauthors have done an excellent job of piecing this history together. They carefully describe the pharmacology of these medications and their success in reducing the risk of fracture in patients with osteoporosis. In addition, they clearly highlight the potential for over suppression of the bone with prolonged administration. They also provide a well-thought-out rationale for institution of an interruption of treatment or holiday in the prescription of these drugs. This article will equip the reader with a current understanding of these medications as well as an algorithm for becoming a better steward in the prevention of a crippling but likely, preventable disease. We will be having a webinar on this topic so, stay tuned for more information. I hope you find it valuable to your practice.

\section{Compliance with Ethical Standards}

Conflict of Interest: Charles N. Cornell, MD reports personal fees from Weitz and Luxemberg, P.C., during the conduct of the study.

Human/Animal Rights: This article does not contain any studies with human or animal subjects performed by the any of the authors.

Informed Consent: N/A

Required Author Forms Disclosure forms provided by the authorsare available with the online version of this article. 